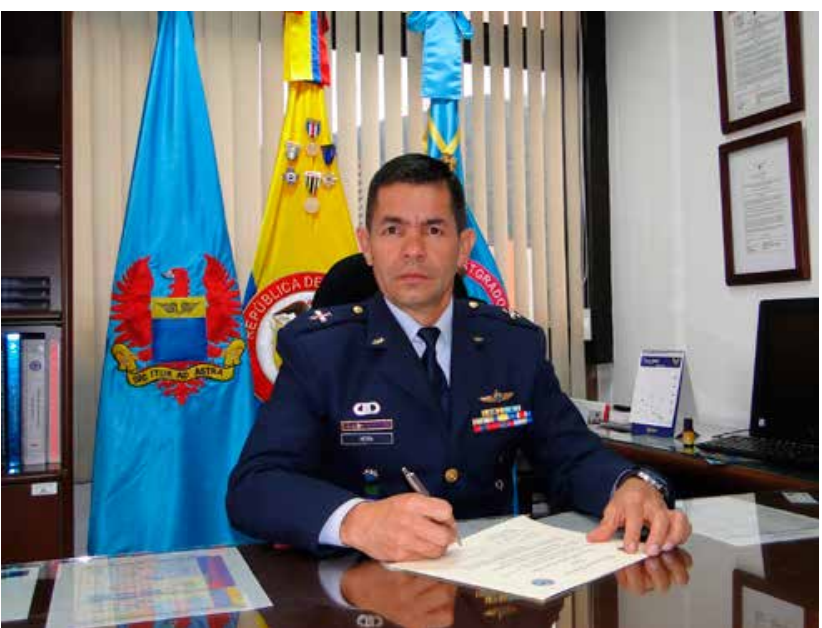

Coronel Javier Neira Peraza Director Escuela de Postgrados FAC

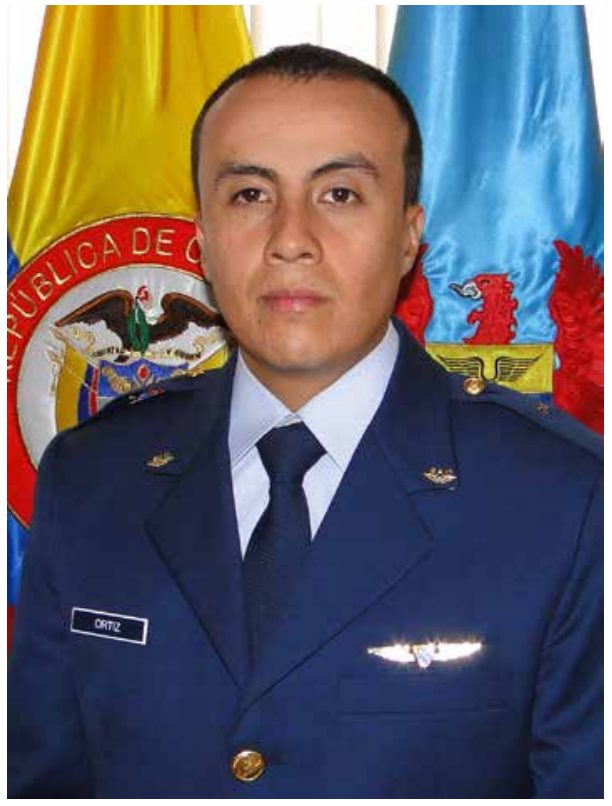

Subteniente Abraham Ortiz Miranda Investigador Escuela de Postgrados FAC

\section{Presentación Arqueología del Conocimiento}

¿Por qué el humano realiza intrincados procesos de conocimiento? ¿A quién o a qué rinde cuentas el conocimiento humano? ¿Cuál es el propósito de este conocimiento? Múltiples preguntas, como las aquí consignadas, son las que han embargado históricamente a los pensadores y científicos en el desarrollo de la filosofía de la ciencia, la epistemología y gnoseología. En el trasegar de la existencia humana, las reflexiones sobre la delimitación, naturaleza y origen del conocimiento se han visto sometidas al crisol del continuo devenir de las circunstancias históricas, dificultando tan ardua labor la constante e intricada naturaleza nuestra, finiti autem imperfectus'.

Sin embargo, el desarrollo de conocimiento tiene un fin en el humano, presenta objetivos claros y responde a situaciones específicas de espacio-tiempo en las que cualquier persona se puede ver inmerso. No obstante, su gestación y duración se han llegado a cuestionar desde una perspectiva de lo infravalorado al considerarlo en el plano de lo banal de la existencia. A pesar de lo anterior, nos dedicamos a los gajes del pensamiento debido al menester de facto que tenemos del mismo.

La naturaleza humana se ve imbuida en la realidad nativa de la constante satisfacción de necesidades, insuficiencias estas que deben ser observadas y solventadas para que la vida tenga cabida. En el entorno que nos desenvolvemos, la Historia per se ha demostrado que todo aquello que existe está sujeto a constantes cambios, no importando su duración. Sin embargo, a parte de sus procesos neuronales, el humano ha sido la única especie en la tierra que no se le dotó de instrumentos corpóreos que le permitan la consecución de sus fines, los cuales propenden por brindarle bienestar, plenitud y felicidad al individuo. No le fueron otorgados extremidades, dones e instrumentos tales como garras, velocidad, colmillos, fuerza superior o capacidades de vuelo que le permitan conseguir alimentos por sus propios medios físicos, solo por poner un ejemplo. Es así, que desde el primer día en que el hombre es concebido, se ha valido de su inteligencia para desarrollar estrategias, caminos, instrumentos, desarrollos y demás, lo que le ha permitido que a su paso por este plano terrenal este lo más libre posible de obstáculos y dificultades.

Con el objeto de promover el desarrollo del conocimiento, el Comité Editorial de la Revista Ciencia y Poder Aéreo exhibe al público el presente número. Para lo cual, la Escuela de Postgrados de la Fuerza Aérea Colombiana, por medio del contemplado volumen, pretende poner al alcance de la sociedad las investigaciones en materia aeronáutica sabiendo que,

$1 \quad$ Traduce del latin finito e imperfecto 
en sus limitaciones, permite a nuestros lectores encontrar en la aviación y en todo lo que ésta abarca, respuestas claves para la satisfacción de necesidades, sobre todo para los territorios más distantes de la geografía nacional.

\section{Subteniente Abraham Ortiz Miranda² \& Coronel Javier Neira Peraza ${ }^{3}$ Director Escuela de Postgrados de la Fuerza Aérea Colombiana}

2 Profesional en Historia de la Universidad Nacional - Oficial Historiador Fuerza Aérea Colombiana. Correo electrónico: abraham.ortiz@epfac.edu. co y aortizmiranda@gmail.com

3 Oficial de Especialidad Defensa Aérea de la Fuerza Aérea Colombiana Administrador Aeronáutico de la EMAVI y Administrador de Empresas de la Universidad Militar Nueva Granada y Especialista en Logística Aeronáutica de la Escuela de Postgrados de la Fuerza Aérea Colombiana. Correo electrónico: Jneirap@gmail.com

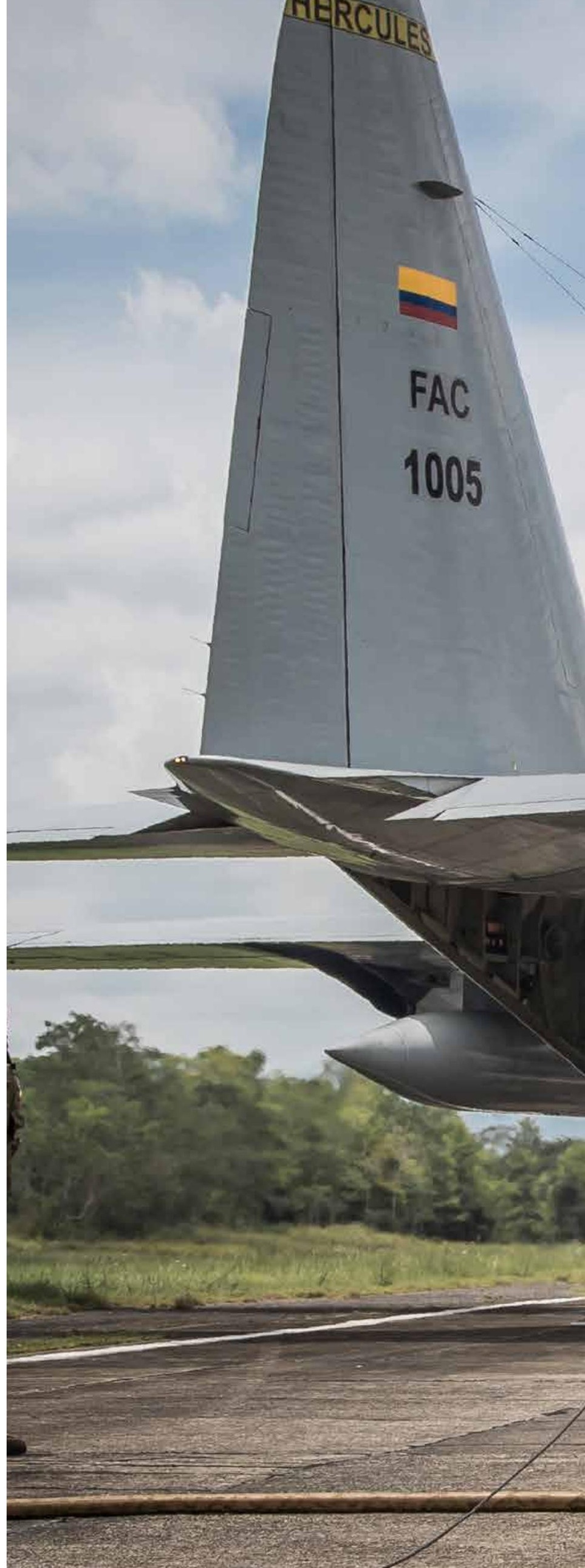

